\title{
Innovation and Communication Media in Virtual Teams - An Experimental Study
}

\author{
Nicola Grözinger, ${ }^{*}$ Bernd Irlenbusch, ${ }^{\dagger}$ Katharina Laske, ${ }^{\ddagger}$ and Marina Schröder ${ }^{\S}$
}

May, 2020

\begin{abstract}
In a novel real-effort setting, we experimentally study the effects of different communication media on creative performance in a collaborative tasks. We find that creative performance significantly decreases when group members communicate via chat instead of face-to-face. However, we find no significant difference between performances of groups that communicate via video conferences as compared to face-to-face. Thus, we provide evidence that barriers to creativity in virtual teams can be mitigated by real-time video conference communication.
\end{abstract}

JEL-Classification; C91; J30; M52; O30

Keywords: Creativity, Communication, Laboratory Experiment, Real-effort, Complex Problem Solving, Innovation

*University of Cologne, Faculty of Management, Economics and Social Sciences, Albertus-Magnus-Platz, 50923 Cologne, Germany.

†University of Cologne, Seminar of Corporate Development and Business Ethics, Albertus-Magnus-Platz, 50923 Cologne, Germany, Email: irlenbusch@wiso.uni-koeln.de.

¥University of Cologne, Faculty of Management, Economics and Social Sciences, Albertus-Magnus-Platz, 50923 Cologne, Germany, Email: laske@wiso.uni-koeln.de.

${ }^{\S}$ Corresponding author. University of Hannover, Institute of Economic Policy, Chair in Innovation Economics, Königsworther Platz 1, 30167 Hannover, Germany, Email: schroeder@wipol.uni-hannover.de. 


\section{Introduction}

The lockdown that became necessary because of the current coronavirus pandemic is associated with immense economic costs (IMF, 2020). Simultaneously, it fosters the adoption of new routines and technologies to conduct collaborative tasks when team members work from home. Many see the latter as positive since working from home has been associated with performance increases in some settings (see, for example, Bloom et al., 2015). Others speculate that working from home is overrated (see, for example, Useem, 2017). In an article The New York Times, for example, writes: "Home-cooked lunches and no commuting while we deal with coronavirus can't compensate for what's lost in creativity" (Roose, 2020). The author argues that what remote workers gain in productivity, they often miss in harder-to-measure benefits like creativity and innovative thinking. One reason for a decrease in creativity and innovative thinking when working from home might be that nowadays innovation is rarely an individual task but mostly needs team collaboration (Amabile and Khaire, 2008, Zhou and Hoever, 2014). Team collaboration might be different if each team member works from home (Krumm et al., 2016). Therefore, in this paper, we take first steps to approach the question of how different communication media affect performance of teams working on a creative task that requires collaboration. We introduce a novel experimental design that mimics many important features of the idea generation stage of an innovation process in which tasks of individual members are highly interdependent. In three treatments, we compare non-remote face-to-face communication to remote communication through video conferences and remote communication through chat. We provide evidence that creative performance under chat communication is significantly lower, as compared to under face-to-face communication. However, this gap in performance in virtual teams appears to be mitigated when employing video conference communication. In particular we find that the share of excellent ideas is significantly larger in the video conference and the face-to-face treatments as compared to the chat treatment, respectively.

To this point, the creative performance of virtual teams in collaborative tasks has rarely been studied. Empirical studies reveal that geographical co-location is an important factor facilitating and accelerating the innovation process (Herbsleb et al., 2000; Johnson et al., 2006; Powell and Giannella, 2010). In this paper we focus on a potential reason why geographical co-location facilitates the innovation process, i.e., the ease and richness of communication. Thus, we systematically vary the communication media through which teams interact in an innovation process. 
Previous research in experimental economics reveals a positive effect of media richness on coordination (Frohlich and Oppenheimer, 1998; Bohnet and Frey, 1999; Cason and Mui, 2015), cooperation (Bohnet and Frey, 1999; Brosig et al., 2003; Charness and Gneezy, 2008; Greiner et al., 2014; He et al., 2017), honesty (Conrads and Lotz, 2015), trust (Charness and Dufwenberg, 2006), and quality of decision making (O’Neill et al., 2016). With respect to the mechanisms through which media richness is important, research in experimental economics has mainly focused on differences in cues provided with respect to the type of person one is interacting with (Bohnet and Frey, 1999; Charness and Gneezy, 2008; Belot et al., 2012; He et al., 2017; Guegan et al., 2017). However, in tasks requiring collaboration, the richness of the information transmitted is also likely to play a role (O’Neill et al., 2016). In line with this interpretation, the positive effect of media richness on performance has been shown to increase as tasks become more collaborative (Straus and McGrath., 1994).

In contrast, research on idea generation in tasks that do not require collaboration, suggests a negative effect of media richness on creativity. In fact, there is wide evidence that brainstorming groups perform better, when they do not communicate at all (Diehl and Stroebe, 1987; Mullen et al., 1991) or communicate only in some steps of the process (Girotra et al., 2010). Once groups communicate, less rich communication media lead to better creative outputs as compared to richer media (Dennis and Valacich, 1993; Nijstad et al., 2003; Lamm and Trommsdorff, 1973). This negative effect of communication richness is attributed to productivity blocking and evaluative apprehension. Productivity blocking refers to the fact that some communication media only allow one person to send out verbal or written messages at a time and that other individuals have to stop working while listening (Diehl and Stroebe, 1987; Nijstad et al., 2003). This productivity blocking is lower whenever communication media allow for simultaneous communication and for a time delay between receiving and encoding a message. Evaluative apprehension refers to the fear of negative evaluation of ideas (Amabile, 1996; Leenders et al., 2003). Previous research shows that evaluative apprehension is positively related to media richness, suggesting that richer media lead to lower creativity (Dennis and Valacich, 1993; Cooper et al., 1998; Kerr and Murthy, 2004). Importantly, this research focuses on creative tasks that can be performed by individuals. Successful innovation, however, often requires both creative performance but also highly interdependent collaboration of specialists from different fields (Dulebohn and Hoch, 2017).

We introduce a novel experimental paradigm to test for the effect of media richness on group performance in a collaborative creative task. Participants in our experiment are randomly assigned to groups of three to work on a creative task, which is a modified online version of the 
task introduced by Laske and Schröder (2017). We instruct experimental participants to use a predefined set of objects to illustrate self-chosen notions, i.e., words. Importantly, group members in our experiment are specialized, i.e., each group member is assigned capabilities to contribute to the illustration in a way that cannot be substituted by a different team member. To be more specific each function can only be performed by one individual in the group. Therefore, in our design team members are highly interdependent, and cooperation is crucial for success, while freeriding of one group member leads to failure of the whole group. Between treatments, we vary the richness of media through which group members communicate. We conduct one treatment, in which group members sit together in one room and communicate face-to-face (high in media richness), one in which they sit in different rooms (remote work) and can only communicate through video conferences (medium in media richness), and one in which they also sit in different rooms (remote work) and can only communicate through real-time chat (low in media richness).

The experimental design that we introduce captures many important features of the idea generation stage of an innovation process. By definition, innovation requires the invention of something "new" (see e.g. Schumpeter, 1942). In our experimental design, we measure and incentivize 'novelty' as the uniqueness of the illustrated words benchmarked against a set of 100 illustrations created in a previous experiment. Invention becomes an innovation only when it is put to productive use, i.e., innovation has to generate economic value (see e.g. Schumpeter, 1942). The value generated, e.g., by a product innovation, crucially depends on (i) the product's usefulness for the customer and/or (ii) how much customers enjoy the innovative product (see e.g., Cooper and Kleinschmidt, 1987). To obtain measures for the usefulness, we ask online participants to identify the illustrated word. To induce an actual usefulness to the online raters, these online participants are paid according to their success in recognizing the illustrated word. We ask another set of online participants to assess the 'enjoyment' provided by the illustration, i.e., we ask about its perceived aesthetic value. To study innovation, the number of positive outliers is a more appropriate success measure rather than average creative performance (see, e.g., Girotra et al., 2010 or Terwiesch and Ulrich, 2009). Thus, in our analysis we particularly focus on the number of excellent illustrations, i.e., ideas that score high on a combined measure of uniqueness, usefulness and aesthetic value.

We find that the share of excellent illustrations is significantly larger in the video conference and the face-to-face treatments as compared to the chat treatment, respectively. To understand the mechanisms driving this result, we additionally study treatment effects on the separate measures. We find no significant treatment differences in uniqueness and the aesthetic value. 
The data show, however, that illustrations generated by groups who could only communicate via chat are significantly less likely to be recognized by online raters as compared to those generated by groups communicating face-to-face or via a video conference.

To the best of our knowledge, we are the first to experimentally study the effect of media richness on performance in a collaborative creative task. Our findings provide an important contribution to the experimental research on cooperation and to the research on idea generation. Our findings have direct practical implications suggesting that organizations should foster video conference communication in order to support innovation and mitigate negative effects of virtual collaboration.

\section{Experimental Design and Procedure}

In our experiment, three randomly matched participants are assigned to one group. Within groups, each member is randomly assigned a role: A, B or C. The groups are instructed to illustrate words by combining a given set of objects provided on the screen by a dedicated online tool. Figure 1 displays the set of icons consisting of twelve colored dots (three each in yellow, red, green and blue), four bold brown lines, four black lines, six quarter circles in black, and two full circles in black. ${ }^{1}$ Groups had to come up and coordinate upon a word, which they wanted to illustrate and a way of illustrating this word with the given materials.

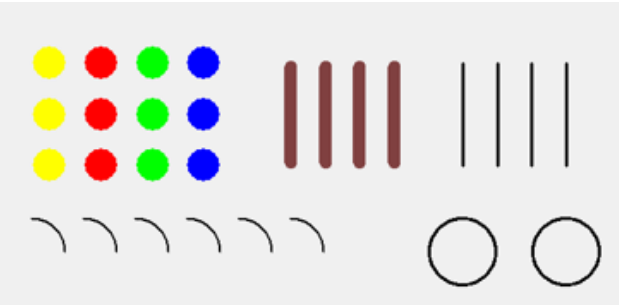

Figure 1: Set of objects

The groups can use a subset or all of these objects for an illustration. We instructed all participants that each illustrated word has to consist of a single term and that illustrations of words comprising of multiple terms (e.g., black sheep or a smiling face) would be invalid. Furthermore, participants were informed that illustrations may not depict any characters

\footnotetext{
${ }^{1}$ The objects on the screen mimic the set of physical materials provided in the design by Laske and Schröder (2017).
} 
displayed on the keyboard of the computer in front of them, i.e., participants are not allowed to use the materials to spell a word. Lastly, the word illustrated had to be included in the standard German dictionary "Duden.” See Online Appendix for the exact instructions of the lab experiment.

Each group member A, B, C was assigned a unique capability or function, which he or she could operate but no one else in the group. Group member A could move icons which included dragging and dropping icons and changing the level of arrangement. Group member B could rotate objects. Group member $\mathrm{C}$ could alter the size of the objects.

Once a group had completed an illustration, group members were asked to type in the illustrated word and to save it. The illustration could only be saved if all group members confirmed the word that was proposed by one of the group members.

Time to perform the task was limited to 30 minutes and groups could save as many illustrations as they wanted within this limited time frame. When the working time was over, all saved illustrations were displayed on the screen of each group member and the groups were asked to select a single illustration which they wanted to be payoff relevant. This selection was only valid when all three group members agreed on the same illustration.

Payment of group members depended on the uniqueness, the usefulness and the aesthetic value of illustrations. In our metric, uniqueness is a binary variable and measured by comparing the word illustrated by a group to the 100 most frequently illustrated words in a companion experiment by Laske and Schröder (2017). An illustration is unique if the illustrated word is not among the 100 most frequently illustrated words and is considered as not unique otherwise. We assessed usefulness through the recognition rate of the illustrated words in a subsequent online experiment. In this online-experiment, we displayed illustrations to random, third-party raters who did not take part in any previously related experimental study and asked these raters to identify the word that is illustrated. See Online Appendix for the instructions and the setup of this online rating-survey. To incentivize behavior of online raters, payment of raters depended on the number of correctly identified words. Thus, raters in our experiment mimic customers whose benefit from innovation increases as the usefulness increases. A word is considered as correctly identified whenever the term indicated by a rater matches that entered by the group who composed the illustration. ${ }^{2}$ Each illustration is rated by 10 independent online

\footnotetext{
${ }^{2}$ Synonyms were not accounted for in the assessment of the recognition rate since we instructed participants of both the lab experiment and the online survey that the payment is only made in case of an exact match of the illustrated word and the online raters' answer. Spelling errors were not corrected and ä, ö, ü and $\beta$ were standardized to a, o, u and ss, respectively. We did not account for the capitalization of letters.
} 
raters. The number of times an illustrated word was correctly identified constitutes our measure for usefulness, which can have integer values in the interval from 0 to 10.

We assess the aesthetic value of illustrations through an online survey in which we ask independent raters to assess the aesthetic value on a scale from 0 (very low aesthetic value) to 10 (very high aesthetic value). Respondents to this survey did not participate in any previous related experimental study and received a fixed payment. Our measure for the aesthetic value corresponds to the average of these three assessments. Figure 2 displays examples of illustrations from our experiment and assigned measures for uniqueness, usefulness and aesthetic value.

$\begin{array}{ccc}\text { Unique } & \text { Highly recognizable } & \text { Highly aesthetic } \\ \text { word illustrated } & \text { illustration } & \text { Illustration }\end{array}$

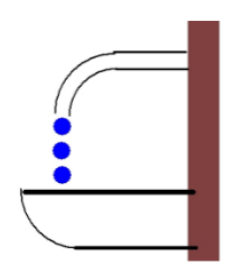

illustrated word: washbasin uniqueness: 1

usefulness: 2 aesthetic: 5.43

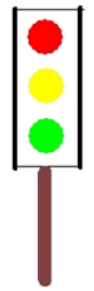

illustrated word: traffic light uniqueness: 0

usefulness: 10 aesthetic: 2.5

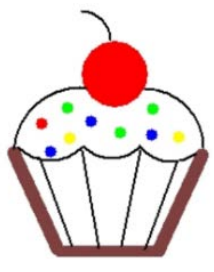

illustrated word: muffin uniqueness: 1 usefulness: 9 aesthetic: 9.6

Figure2: Examples of illustrations with assigned measures for uniqueness, usefulness, and aesthetic

Payment of all group members was based on the combined innovation measure of the idea generated. This combined innovation measure is the usefulness measure plus the aesthetic value in case an illustrated word was unique. If the word illustrated was not unique, the combined innovation measure is equal to zero. Thus, the combined innovation measure is defined as uniqueness*(aesthetic value + usefulness). Payment could range from 0 Euro to 20 Euro. Additionally, all participants received a fixed show up fee of 4 Euro. Finally, all group members of the group that created the illustration with the highest payoff from the entire experiment received an extra bonus of 100 Euro. These incentives and the measurement procedure were common information among the group members. 
Between treatments, we varied the media through which participants could communicate. In the face-to-face treatment (high media richness), the three group members were in the same room and could speak with each other and see each other during the entire experiment. In the video conference treatment (medium media richness), group members were in separate rooms and could only communicate with each other via video conferencing. In the chat treatment (low media richness), group members were in separate rooms and could only communicate with each other via chat during the experiment. Table 1 summarizes the experimental treatments and indicates the number of valid group observations (and the number of participants) in each treatment. $^{3}$

Table 1: Treatment overview

\begin{tabular}{lllr}
\hline Treatment & Communication channel & Media richness & $N(\boldsymbol{n})$ \\
& & & \\
Face-to-face & Interaction involving physical presence without & High & $30)$ \\
& mediating technology & & $30(90)$ \\
Video conference & Interaction via audio and video communication & Medium & $28(84)$ \\
\hline
\end{tabular}

The experiment was carried out at the University of Cologne. The participants for the experiment were recruited via the Online Recruitment System for Economic Experiments (ORSEE) (Greiner, 2004). A total of 92 groups comprising 276 participants took part in the experiment.

All participants of the experiment were seated in front of an individual computer and confronted with the same software to create illustrations. Instructions were provided on screen. Average payment was 7.74 Euro. The fixed payment of 4 Euro was payed directly after the experiment. The performance-dependent payment was made via bank transfer three weeks after completion of the experiment.

\footnotetext{
${ }^{3}$ Across the treatments, 4 group observations had to be excluded from the analysis due to the use of keyboard characters, no agreement on one illustration relevant for payment or a technical defect while saving the illustration.
} 


\section{Results}

For innovation, it is typically not the average performance, but the positive outliers, which lead to success (see, e.g., Giotra et al., 2010 or Terwiesch and Ulrich, 2009). To account for this fact, we primarily focus on the likelihood of the creation of excellent illustrations. In our measure of excellent illustrations, we consider all illustrations with a combined innovation measure, which is above the 50th percentile from all illustrations submitted. Figure 3 displays the share of excellent illustrations in each treatment separately. We find that the share of excellent illustrations is significantly larger in the video conference and the face-to-face treatments as compared to the chat treatment, respectively (pairwise Fisher-Exact, $p<0.10$ ).

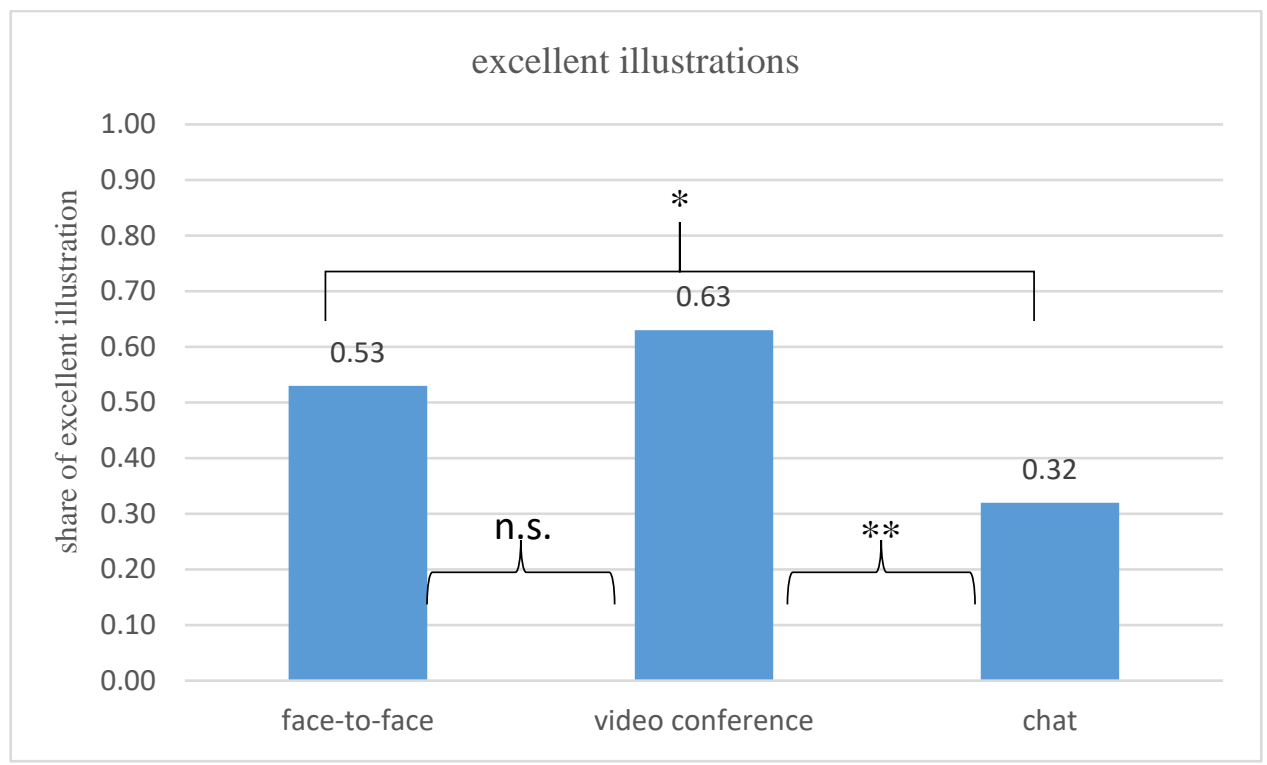

We report two-tailed significance levels of Fisher-Exact tests comparing the fraction of excellent ideas as brackets between the bars. Where ${ }^{* *} p \leq 0.05,{ }^{*} p<0.10$.

Figure 3: Share of excellent illustrations

To shed more light on this main finding, we compare the performance in our separate innovation dimensions, i.e., uniqueness, the aesthetic value and usefulness. Figure 4 provides an overview of treatment comparisons. We find that the fraction of groups that come up with unique ideas tends to be largest in the chat treatment. However, differences are not significant. We also do not find significant treatment differences in the aesthetic values of illustrations. However, we do find that usefulness substantially varies between treatments. Illustrations generated by groups communicating via chat are recognized by significantly fewer online raters as compared to illustrations generated by groups communicating face-to-face or via video-conference (U- 
test, $p<0.05)$. Last, we find no significant differences when it comes to the combined innovation measure.

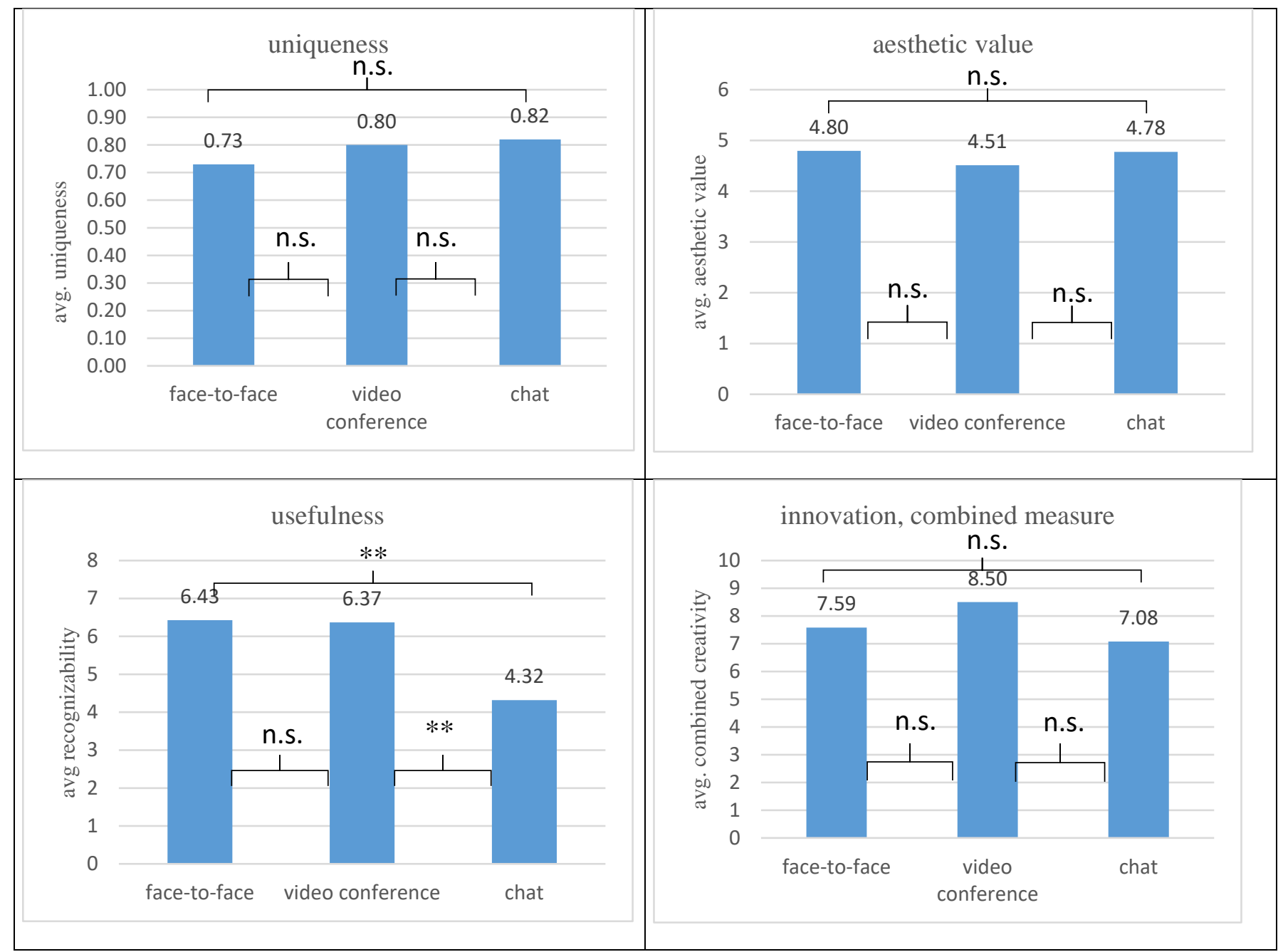

Figure 4: Performance in the Separate Dimensions

We report two-tailed significance levels of Fisher-Exact tests for uniqueness and of U-tests for aesthetic value, usefulness and combined innovation as brackets between the bars. Where $* * p \leq 0.05$. See Appendix for confirming regression results.

Figure 4: Performance in separate dimensions

\section{Conclusion and Discussion}

We provide evidence that differences in communication media matters with regard to innovation processes of virtual teams. Team-members who are remote from each other and communicate via video conference - perhaps surprisingly - tend not to perform substantially different from teams that communicate face-to-face in the same room. Compared with these settings, collaborative creative performance, however, tends to be significantly lower, when virtual teams communicate via chat. This is particularly true with regard to the share of excellent 
ideas. Our data reveals that this is mainly due to differences in the usefulness of creativity output and less so with regard to uniqueness and the aesthetic values.

In line with the previous research on idea generation (see e.g., Diehl and Stroebe, 1987; Mullen et al., 1991), our findings seem to suggest that virtual communication among team members has a positive (although not significant) effect on the uniqueness of ideas. To come up with a unique word, collaboration is not necessary and thus, the positive effects of reducing productivity blocking and evaluative apprehension seem to prevail. However, when it comes to usefulness, collaboration becomes highly relevant. For this dimension, the benefits of rich media, i.e., improvements in cooperation and group decision making (see e.g., Brosig et al., 2003; He et al., 2017), seem to prevail. In the combined innovation measure, we find that video conference communication appears not to be inferior to face-to-face communication. In fact, it may actually combine the best of both an increase in uniqueness due to remote work and a high level of usefulness achieved due to relatively high media richness.

Our study can only be a first step and further research is needed to disentangle different explanations. We introduce an experimental design that captures many factors that are of high relevance for the innovation process, like high specialization of team members and high interdependence of work tasks. In this respect our design might serve as a workhorse for further studies. We are able to objectively characterize excellent innovative ideas by giving consideration to the uniqueness of the idea, the usefulness of the product and the aesthetic value. Last but not least, our findings can be interpreted in a quite promising way: Virtual teams are not necessarily prone to suffer from low creativity performance if communication media are chosen appropriately. This provides hope that also in lockdowns like those due to the corona pandemic, innovation is possible.

Acknowledgements: We thank Emanuel Castillo-Ruiz for support in programming this experiment and Sarah Adelfang for assistance in running the experiment. Financial support from the Deutsche Forschungsgemeinschaft through grant of sub-project TP3 of the DFG-Forschergruppe 'Design and Behavior’, FOR1371 and Germany’s Excellence Strategy EXC 2126/1-390838866: “ECONtribute: Markets and Public Policy” is gratefully acknowledged. Nicola Grözinger joined this project after completion of data collection. In the context of her Master's thesis (Grözinger, 2019), she provided a first analysis of the data. 


\section{References}

Amabile, T. M. (1996). Creativity in Context. New York: Westview Press.

Amabile, T. M., \& Khaire, M. (2008). Your organization could use a bigger dose of creativity. Harvard Business Review, 86(10), 101-109.

Belot, M., Bhaskar, V., \& Van De Ven, J. (2012). Can observers predict trustworthiness?. Review of Economics and Statistics, 94(1), 246-259.

Bloom, N., Liang, J., Roberts, J., \& Ying, Z.J. (2015). Does Working from Home Work? Evidence from a Chinese Experiment. The Quarterly Journal of Economics, 130(1),165218.

Bohnet, I., \& Frey, B. S. (1999). Social distance and other-regarding behavior in dictator games: Comment. American Economic Review, 89(1), 335-339.

Brosig, J., Weimann, J., \& Ockenfels, A. (2003). The Effect of Communication Media on Cooperation. German Economic Review, 4(2), 217-241.

Cason, T. N., \& Mui, V. L. (2015). Rich communication, social motivations, and coordinated resistance against divide-and-conquer: A laboratory investigation. European Journal of Political Economy, 37, 146-159.

Charness, G., \& Dufwenberg, M. (2006). Promises and partnership. Econometrica, 74(6), 1579-1601.

Charness, G., \& Gneezy, U. (2008). What's in a Name? Anonymity and Social Distance in Dictator and Ultimatum Games. Journal of Economic Behavior \& Organization, 68(1), 29-35.

Conrads, J., \& Lotz, S. (2015). The effect of communication channels on dishonest behavior. Journal of Behavioral and Experimental Economics, 58, 88-93.

Cooper, W. H., Gallupe, R. B., Pollard, S., \& Cadsby, J. (1998). Some Liberating Effects of Anonymous Electronic Brainstorming. Small Group Research, 29(2), 147-178.

Cooper, R. G., \& Kleinschmidt, E. J. (1987). Success factors in product innovation. Industrial marketing management, 16(3), 215-223.

Dennis, A. R., \& Valacich, J. S. (1993). Computer Brainstorms: More Heads Are Better Than One. Journal of Applied Psychology, 78(4), 531-537.

Diehl, M., \& Stroebe, W. (1987). Productivity loss in brainstorming groups: Toward the solution of a riddle. Journal of personality and social psychology, 53(3), 497.

Dulebohn, J. H., \& Hoch, J. E. (2017). Virtual teams in organizations. Human Resource Management Review, 27(4), 569-574.

Frohlich, N., \& Oppenheimer, J. (1998). Some Consequences of E-Mail vs. Face-to-Face Communication in Experiment. Journal of Economic Behavior \& Organization 35(3), 389-403.

Girotra, K., C. Terwiesch, \& K.T. Ulrich (2010). Idea Generation and the Quality of the Best Idea. Management Science, 56(4), 591-605.

Greiner, B., Caravella, M., \& Roth, A. E. (2014). Is Avatar-to-Avatar Communication as Effective as Face-to-Face Communication? An Ultimatum Game Experiment in First and Second Life. Journal of Economic Behavior \& Organization, 108, 374-382. 
Greiner, B. (2004). An Online Recruitment System for Economic Experiments. Forschung und wissenschaftliches Rechnen 2003. GWDG Bericht, 63, 79-93.

Grözinger, N. (2019). How Does Virtuality Affect the Creative Performance of Teams? An Experimental Investigation.

Guegan, J., Segonds, F., Barre, J., Maranzana, N., Mantelet, F., \& Buisine, S. (2017). Social identity cues to improve creativity and identification in face-to-face and virtual groups. Computers in Human Behavior, 77, 140-147.

He, S., Offerman, T., \& van de Ven, J. (2017). The sources of the communication gap. Management Science, 63(9), 2832-2846.

Herbsleb, J. D., Mockus, A., Finholt, T. A., \& Grinter, R. E. (2000). Distance, dependencies, and delay in a global collaboration. Proceedings of the 2000 ACM conference on Computer supported cooperative work (pp. 319-328).

IMF (2020). World Economic Outlook, April 2020, Chapter 1. Retrieved from www.imf.org.

Johnson, D. K., Siripong, A., \& Brown, A. S. (2006). The demise of distance? The declining role of physical proximity for knowledge transmission. Growth and Change, 37(1), 1933.

Kerr, D. S., \& Murthy, U. S. (2004). Divergent and Convergent Idea Generation in Teams: A Comparison of Computer-Mediated and Face-to-Face Communication. Group Decision and Negotiation, 13(4), 381-399.

Krumm, S., Kanthak, J., Hartmann, K., \& Hertel, G. (2016). What does it take to be a virtual team player? The knowledge, skills, abilities, and other characteristics required in virtual teams. Human Performance, 29(2), 123-142.

Laske, K., \& Schroeder, M. (2017). Quantity, Quality and Originality: The Effects of Incentives on Creativity.

Leenders, R. T. A., Van Engelen, J. M., \& Kratzer, J. (2003). Virtuality, Communication, and New Product Team Creativity: A Social Network Perspective. Journal of Engineering and Technology Management, 20(1-2), 69-92.

Mullen, B., Johnson, C., \& Salas, E. (1991). Productivity loss in brainstorming groups: A metaanalytic integration. Basic and applied social psychology, 12(1), 3-23.

Roose, K. (2020). The Shift. Sorry, but Working From Home Is Overrated. New York Times. 10 March 2020. nyti.ms/3aHNVbr.

Nijstad, B. A., Stroebe, W., \& Lodewijkx, H. F. (2003). Production Blocking and Idea Generation: Does Blocking Interfere with Cognitive Processes? Journal of Experimental Social Psychology, 39(6), 531-548.

O’Neill, T. A., Hancock, S. E., Zivkov, K., Larson, N. L., \& Law, S. J. (2016). Team decision making in virtual and face-to-face environments. Group Decision and Negotiation, 25(5), 995-1020.

Powell, W. W., \& Giannella, E. (2010). Collective invention and inventor networks. In Handbook of the Economics of Innovation (Vol. 1, pp. 575-605). North-Holland.

Schumpeter, J. A. (1942). Socialism, capitalism and democracy. Harper and Brothers.

Straus, S. G., \& McGrath, J. E. (1994). Does the Medium Matter? The Interaction of Task Type and Technology on Group Performance and Member Reactions. Journal of Applied Psychology, 79(1), 87-97. 
Terwiesch, C., \& Ulrich, K. T. (2009). Innovation tournaments: Creating and selecting exceptional opportunities. Harvard Business Press.

Useem, J. (2017). When Working from Home Doesn't Work. The Atlantic. November Issue. www.theatlantic.com/magazine/archive/2017/11/when-working-from-home-doesntwork $/ 540660 /$.

Zhou, J., \& Hoever, I. J. (2014). Research on workplace creativity: A review and redirection. Annual Review of Organizational Psychology and Organizational Behavior, 1(1), 333359. 


\section{Appendix}

Table B.1: Treatment differences shown in OLS-regressions

\begin{tabular}{lccccc}
\hline VARIABLES & $\begin{array}{c}(1) \\
\text { excellent ideas }\end{array}$ & $\begin{array}{c}(2) \\
\text { uniqueness }\end{array}$ & $\begin{array}{c}(3) \\
\text { aesthetic value }\end{array}$ & $\begin{array}{c}(4) \\
\text { usefulness }\end{array}$ & $\begin{array}{c}(5) \\
\text { combined } \\
\text { innovation }\end{array}$ \\
\hline video conference & 0.100 & 0.067 & -0.284 & -0.067 & 0.918 \\
& $(0.129)$ & $(0.111)$ & $(0.537)$ & $(0.799)$ & $(1.447)$ \\
chat & -0.212 & 0.088 & -0.022 & $-2.113^{* *}$ & -0.506 \\
& $(0.129)$ & $(0.110)$ & $(0.534)$ & $(0.909)$ & $(1.452)$ \\
Constant & $0.533^{* * *}$ & $0.733^{* * *}$ & $4.797^{* * *}$ & $6.433^{* * *}$ & $7.587^{* * *}$ \\
& $(0.093)$ & $(0.082)$ & $(0.418)$ & $(0.621)$ & $(1.094)$ \\
Observations & 88 & & & 88 & 88 \\
R-squared & 0.066 & 0.008 & 0.004 & 0.085 & 0.012 \\
\hline
\end{tabular}

OLS regression. Dependent variables: Dummy indicating whether an idea is excellent or not in model 1; dummy indicating whether an idea is unique or not in model 2; avg. aesthetic value in model 3; number of raters correctly identifying the illustrated word in model 4; the combined innovation measure in model (5). We include controls for the treatments as independent variables, where face-to-face communication serves as the baseline. Main results from model 1 and 2 are robust to corresponding probit regression model. Robust standard errors in parentheses. *** $\mathrm{p}<0.01,{ }^{* *} \mathrm{p}<0.05,{ }^{*} \mathrm{p}<0.1$ 


\title{
Online Appendix: Details Experimental Procedure
}

\author{
Instructions lab experiment (translation from German) \\ Instructions
}

In the following, you work in a group of three consisting of group members A, B and C. All group members can see each other and talk to each other (in Chat treatment: chat with each other) during the whole experiment. You will see the same objects on your respective screens. Your group task is to illustrate words with the given objects. Each illustrated term must consist of exactly one word. Each group member has one or more specific functions when illustrating words which no other group member has. The objects can be placed in the drawing field by group member A of your group, moved there randomly, changed in their arrangement level and returned to the object box. Group member B can rotate the objects. Group member C can enlarge or reduce the respective objects. Which group member you are is shown on the screen.

You have 30 minutes to complete this task. During this time you can illustrate as many words as you like. We kindly ask you to save all the illustrations (instructions will follow). As soon as the working time has expired, the screens of all group members will display all the illustrations saved by your group. Out of these, the best illustration must be selected. This illustration determines your payout and the payment of the other two group members.

\section{Evaluation criteria for illustrations:}

At the end of the experiment, the illustration that you and your group have selected as the best will be evaluated in terms of uniqueness, recognizability and aesthetic value. Your payment will depend on these ratings. The evaluation is explained in detail below:

- Uniqueness: An illustration is unique if the word illustrated is not one of the 100 most frequently illustrated words from a similar previous experiment.

- Recognizability: 10 independent raters try to recognize the word illustrated after the experiment. The judges receive money, if they detect the correct word. We measure the recognizability according to the number of the judges who identify the exact word correctly.

- Aesthetic value: 10 independent raters evaluate the aesthetic value of your illustration on a scale from 0 (very low aesthetic value) to 10 (very high aesthetic value). The aesthetic value of your illustration is calculated from the average of these 10 ratings.

\section{Payment for the illustration}


The word your group has chosen as the best illustration is not unique:

- You and the other group members do not receive any payment for the illustration of the word $(€ 0)$.

The word your group has chosen as the best illustration is unique:

- Each group member receives an additional payment of $€ \mathbf{1}$ per rater who has correctly identified the word illustrated (maximum $€ 10$ ).

- Each group member receives an additional payment in the amount of the determined aesthetic value (maximum $€ 10$ ).

This means that each group member can receive a payment of up to $€ 20$ for the illustration. You will receive your payment within three weeks after this experiment by bank transfer to your specified account.

\section{Examples:}

- The illustrated word is not unique. It is correctly identified by 6 raters and has an aesthetic value of 3.7.

- From the illustration a payment of 0 euro results for you and your team members (the word illustrated is not unique).

- The word illustrated is unique. It is correctly identified by 5 raters. The aesthetic value is 7.4 .

- From the illustration a payment of $€ 12.40$ results for you and your team members $(5 \times € 1$ $+7.4 \times € 1$, since the word illustrated is unique).

Additionally, you have the opportunity to receive a bonus. After this experiment, the illustration with the highest payment will be determined. Each member of the group that has created this illustration receives a bonus of $€ \mathbf{1 0 0}$.

Irrespective of the illustration, each participant of this experiment receives a show-up fee of $€ 4$, which is paid in cash immediately after the experiment.

\section{Procedure of the experiment}

Below you can see screenshots of the respective workspaces of the group members. Under the screenshots we explain the respective functions, which the respective group members can execute as the only ones. 
Group member A can place objects in the drawing field, move them there as desired, change their arrangement level and return them to the object box.

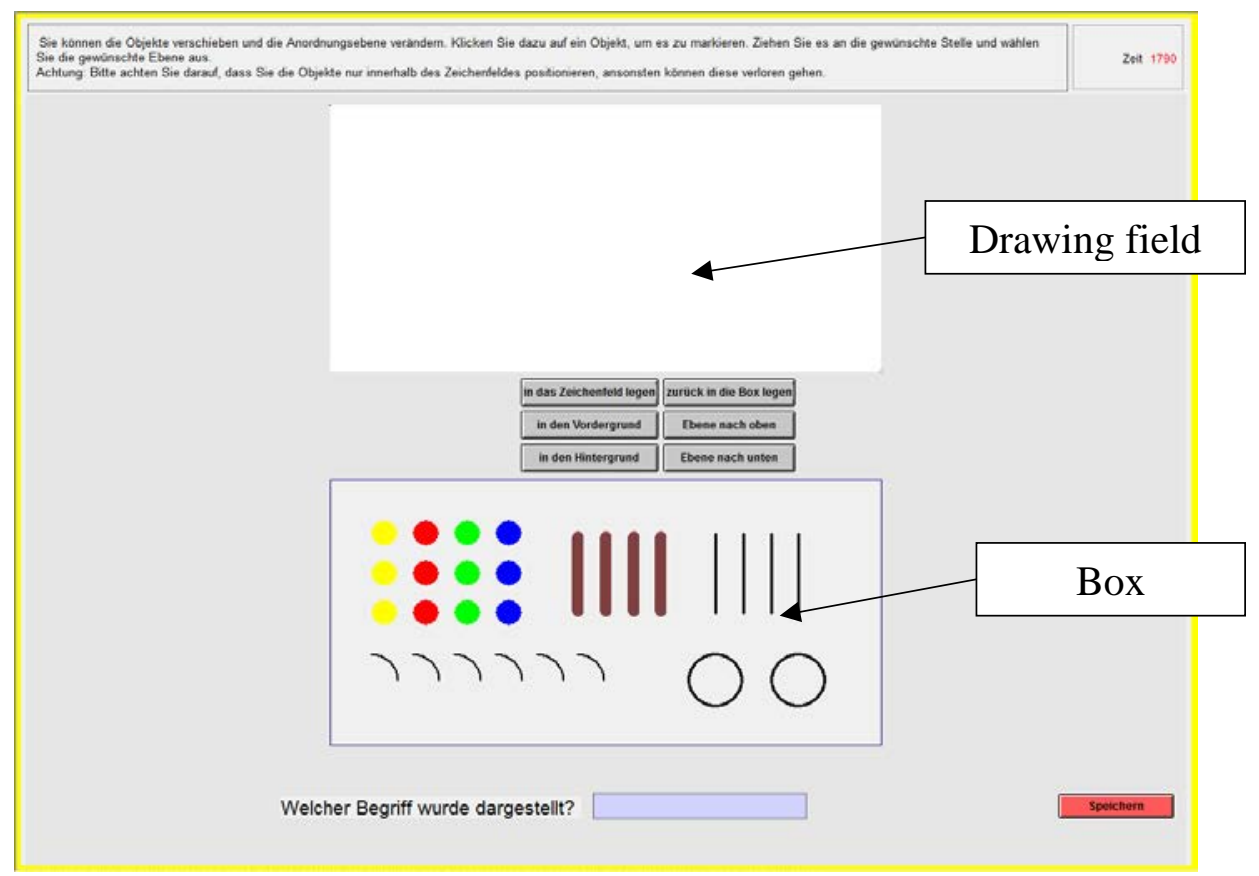

Figure B.1

- Placing objects in the drawing field: This button is used to place the clicked object from the box in the drawing field. You can move the object freely within the drawing field using drag \& drop. Attention: Objects can only be moved within the drawing field using drag \& drop. If you try to move objects outside the drawing field by drag \& drop, e.g. from the box into the drawing field, these objects get lost and are only available again after you have saved a word.

- Putting objects back into the box: With this button the clicked object is put back from the drawing field into the box.

- Moving objects to the foreground: If several objects are on top of each other, the clicked object can be moved to the foreground

- Moving objects into the background: If several objects lie on top of each other, the clicked object can be moved into the background.

- Moving objects one level up: If several objects lie on top of each other, the clicked object can be moved one level up.

- Moving objects one level down: If several objects lie on top of each other, the clicked object can be moved one level downwards. 
Group member B can rotate the objects.

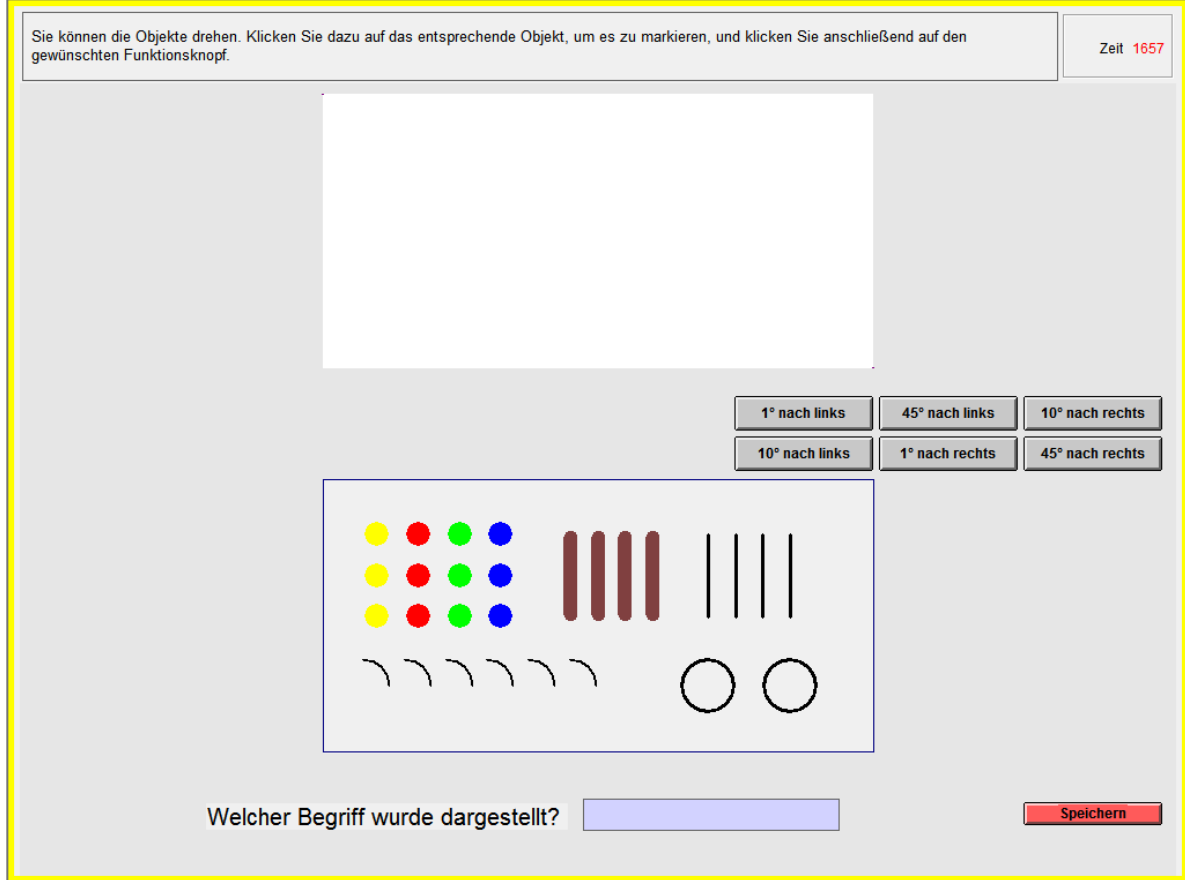

Figure B.2

- $1^{\circ}$ to the left: The clicked object is rotated $1^{\circ}$ to the left.

- $10^{\circ}$ to the left: The clicked object is rotated $10^{\circ}$ to the left.

- $45^{\circ}$ to the left: The clicked object is rotated $45^{\circ}$ to the left.

- $1^{\circ}$ to the right: The clicked object is rotated $1^{\circ}$ to the right.

- $10^{\circ}$ to the right: The clicked object is rotated by $10^{\circ}$ to the right.

- $45^{\circ}$ to the right: The clicked object is rotated $45^{\circ}$ to the right. 
Group member $\mathbf{C}$ can change the size of the objects.

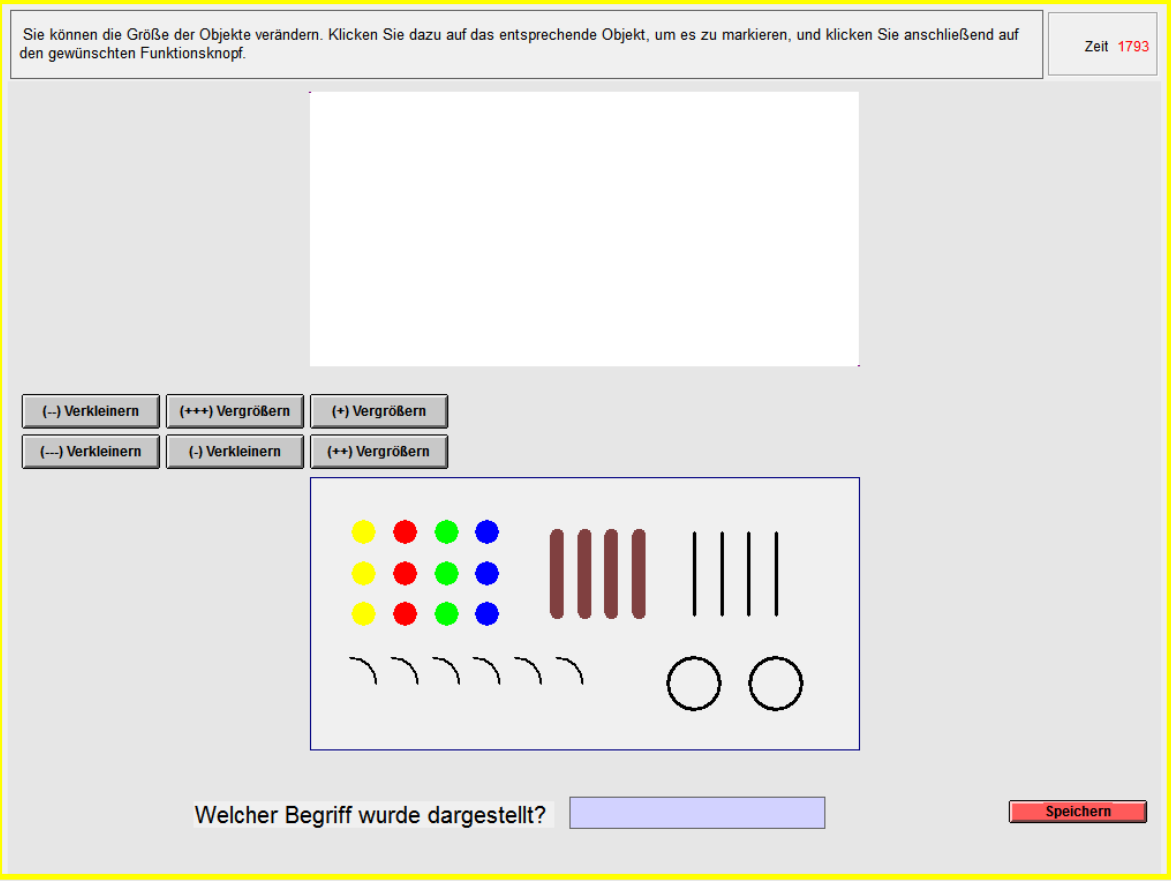

Figure B.3

- (-) Reduce: The clicked object is slightly reduced in size

- (--) Reduce: The clicked object is reduced moderately

- (---) Reduce: The clicked object is strongly reduced in size

- (+) Enlarge: The clicked object is slightly enlarged

- (++) Enlarge: The clicked object is enlarged moderately

- $(+++)$ Enlarge: The clicked object is enlarged strongly 
Please proceed as a group with the illustration of each word as follows:

1. Illustrate a word by using the objects in the drawing field. Always click on the border of the object you want to use to mark it and then click on the button you want to use.

2. Enter the word you have illustrated in the field "Which word was illustrated?" and save it by clicking on "save". Each group member can enter a word in the field and save it.

3. Once a group member has entered and saved a word, the other two group members will be asked for their agreement. Only if all group members agree, the representation will be saved under the entered word. If at least one group member does not agree, you can continue working on the presentation and/or save it under a different word, and all group members will then be asked to agree.

Repeat steps 1-3 for each word illustrated.

Please note the following:

- For each word to be illustrated, you can use all objects from your set or a selection of these objects.

- Please keep the unused objects in the box.

- Illustrate only one word at a time. This means that the name of the illustration may consist of only one word. Terms consisting of several words are not allowed and will not be evaluated.

- Your illustration may not contain any character that is displayed on the keyboard (e.g. representations that contain "", "8", "b", "@", ">" or "+" are not allowed).

- Only illustrate words in the German language, i.e. the terms must be in the German dictionary.

Please proceed as follows to select the best representation:

After the working time (30 minutes) has expired, you and the other two members in your group will be shown all the illustrations that your group has saved during the working time. Your group should select the one that you think is best and that should be relevant to your payment. For an illustration to be selected, each member of your group must select the same illustration as the best one.

Instructions online survey to assess usefulness (translation from German) 


\section{Instructions}

Please carefully read the following instructions. If you have any questions about these instructions or if you have any trouble with the experiment, please contact us by email at internetexperimente@wiso.uni-koeln.de.

Please note that you are not allowed to go back to the previous page at any time during the whole experiment.

In the following, you will see 50 illustrations one after the other on your screen. These illustrations were made by participants of a previous experiment. These participants' task was to illustrate words using materials provided. The words could be chosen freely and had to consist of exactly one word.

\section{Your task:}

Your task is to identify the illustrated words. If you enter the exact word illustrated by another participant, you will receive a payment. If you do not enter a word for an illustration, or if the word you enter does not correspond exactly to the other participant's entry, then you will not receive any payment for this illustration. Please note that each of the illustrated words consists of only one word. Your entries may also consist of only one word each. If you enter more than one word for an illustration, this illustration will be considered as 'not recognized'. Please also note that the words were illustrated by different participants, which means that you may see several different illustrations of the same word.

\section{Payment:}

You will receive your payment only if you complete the entire experiment. You receive $€ 2.00$ for participating in this experiment. In addition, you will receive $€ 0.10$ for each correctly recognized word. You will receive your payment within two weeks after this experiment to your bank account. 


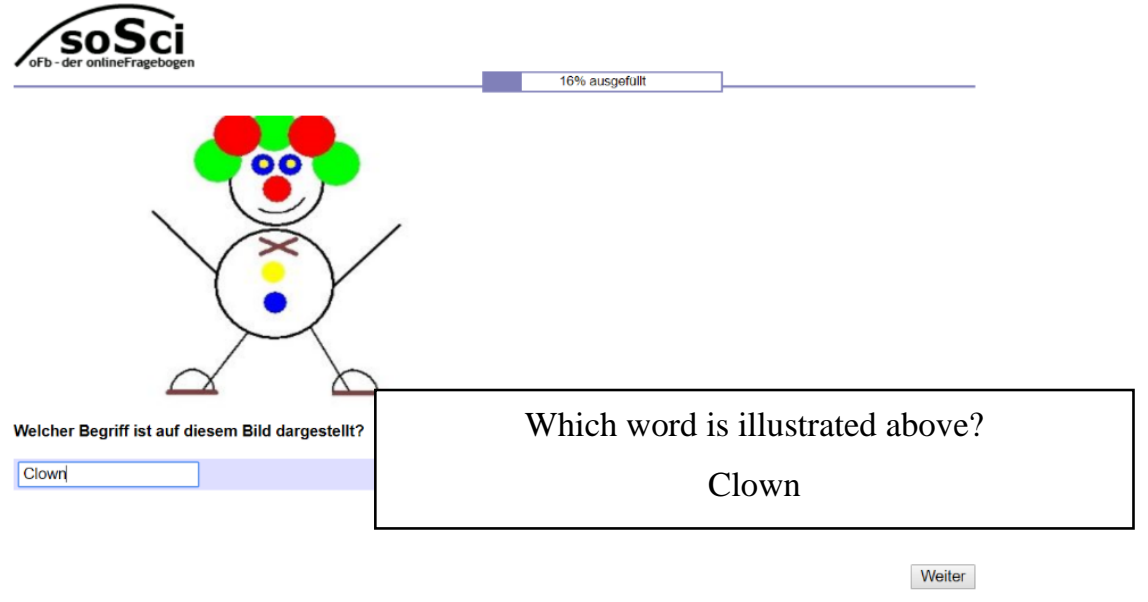

Figure C.1: Screen of survey on usefulness (example) 


\section{Appendix C \\ Instructions online survey to assess usefulness (translation from German) \\ Instructions}

Please carefully read the following instructions before starting the experiment. If you have any questions about these instructions or if you have any trouble with the experiment, please contact us by email at internetexperimente@wiso.uni-koeln.de.

Please note that you are not allowed to go back to the previous page at any time during the whole experiment.

In the following, you will see 44 illustrations one after the other on your screen. These illustrations were made by participants of a previous experiment. The task of these other participants was to illustrate words using given shapes and colors (all participants were given the same shapes and colors). The words could be chosen freely and had to consist of only one word.

\section{Your task:}

Your task is to evaluate the aesthetic value of the illustrations on a scale from 0 (very low aesthetic value) to 10 (very high aesthetic value). The aesthetic value is assessed by how much you like the illustration and how much you enjoy looking at it.

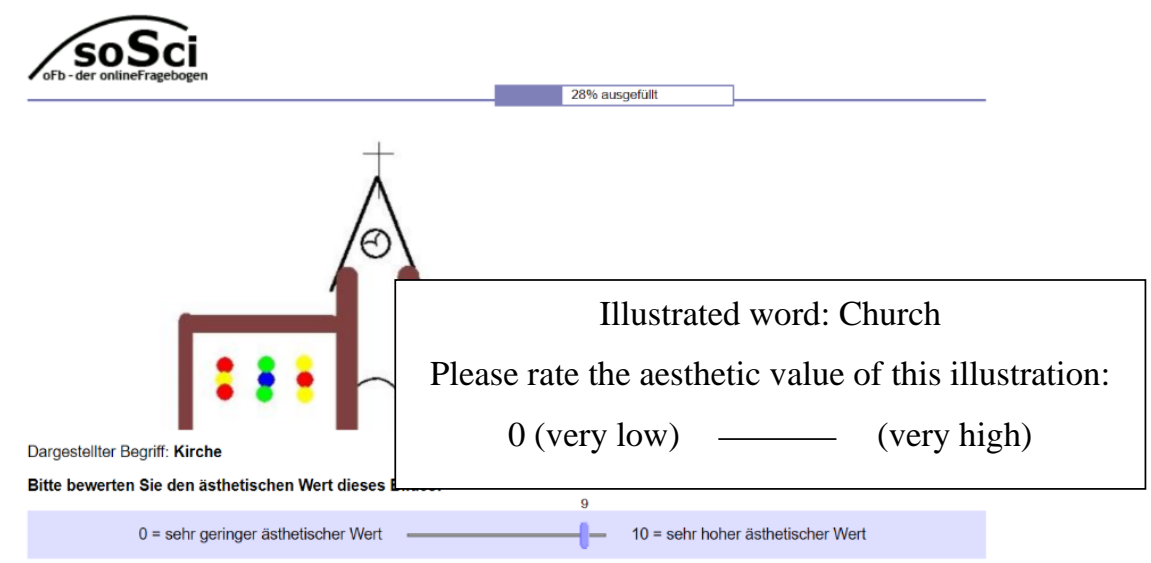

Figure D.1: Screen of survey on aestehtic value (example) 